\title{
II. Patients' and clinicians'preferences
}

\section{Variability in patient preferences for participating in medical decision making: implication for the use of decision support tools}

\author{
A Robinson, $\mathrm{R}$ Thomson
}

\begin{abstract}
While there is an increasing emphasis on patient empowerment and shared decision making, evidence suggests that many patients do not wish to be involved in decisions about their own care. Previous research has found patient preferences for involvement in decision making to vary with age, socioeconomic status, illness experience, and the gravity of the decision. Furthermore, there is evidence that certain patients may experience disutility from being involved in decision making about the treatment of their health problems. We discuss the implications of these findings for the use of decision support tools and the difficulties of targeting their use towards those patients most likely to benefit. We argue that patients may be ill informed about what participation in decision making actually entails and unaware of the benefits they stand to gain by articulating their preferences to their clinician. Furthermore, clinicians are not good at accurately assessing patients' preferences, while patients may have unrealistic expectations about their clinician's ability to "know what is best" for them. Further research is required to understand variations in patients' preferences for information and involvement in decision making, and the factors that influence them.

(Quality in Health Care 2001;10(Suppl I):i34-i38)
\end{abstract}

Keywords: patient preference; informed choice; decision making; patient-caregiver communication

Department of

Epidemiology and

Public Health, School

of Health Sciences,

Medical School,

Newcastle upon Tyne

NE2 4 HH, UK

A Robinson, $M R C$

training fellow

$\mathrm{R}$ Thomson, professor of epidemiology and public

health

Correspondence to:

Dr A Robinson

angela.robinson@newcastle. ac.uk
Key messages

- There is increasing emphasis on patient autonomy and active involvement in decision making.

- Evidence suggests that patients' preferences for receiving information (information evaluation) on treatments and for taking responsibility for treatment decisions varies.

- Factors associated with these preferences include age, sex, and type of clinical problem.

- Clinicians are poor at assessing their patients' preferences for involvement in decision making.

- Equally, patients may not appreciate the implications of involvement in decision making and their preferences may reflect this lack of understanding or reflect past experience of health care.

- These features have potentially profound implications for which patients should be involved in decision making, at what level, and how.

- Further research is required to understand better patients' preferences for involvement in decision making and the factors that may influence them.

patient participation in treatment decision making is "sparse". ${ }^{11}$

Deber discusses the apparent discrepancy between the strong belief in the importance of patient autonomy and the existing empirical literature that appears to suggest that many patients may not wish to be active participants in making treatment decisions. ${ }^{12}{ }^{13}$ The work of Deber and others highlights the need to better understand patient preferences for participating in clinical consultations. In particular, a number of empirical studies have suggested that, even if patients wish to be informed about their condition and options for treatment, they might not wish to be actively involved in making the treatment decision. ${ }^{14-16}$ This distinction between information evaluation and taking responsibility for treatment decisions may be important. 
We discuss the implications of these findings for the use of decision support tools and illustrate our points with findings from our work in Newcastle where we have developed an expected utility based decision analysis tool to support shared decision making for patients in atrial fibrillation. ${ }^{17}$

\section{The doctor-patient relationship}

Before going on to examine patient preferences for information and for participation in decision making, it is necessary to consider various models of the doctor-patient interaction. One conceptual approach used in health economics to describe the doctor-patient relationship is one in which the physician acts as agent for the patient. ${ }^{18-20}$ In this framework the principal (the patient) delegates authority to an agent (the doctor) to make treatment decisions on his behalf. The agency relationship arises because of the asymmetry of information between the doctor, who possesses superior medical information, and the patient, who possesses superior information on his preferences over treatment options. A doctor working as a perfect agent would make the same decision as the patient would were the patient to be party to the same clinical expertise as the doctor. However, such perfect agency relationships rarely exist in practice due to the principal's uncertainty as to the agent's preferences and a lack of incentives to uncover these fully.

Alternatively, styles of consultation may be considered to lie on a spectrum from "paternalistic", which assumes primacy for the doctor's clinical knowledge and makes no (or little) concessions to patients' preferences, through to "informed consent" which (in its purest form) assumes the patient alone will make the treatment decision once he has been given all necessary clinical information. Somewhere between these two extremes lies the notion of shared decision making where the intention is that both the process and outcome of the treatment decision will be shared. Unlike the paternalistic model, both the informed and shared systems of decision making retain the objective of arriving at a treatment decision based on the doctor's knowledge and the patient's preferences. Suggested definitions of each are given in box 1 .

"An informed decision is one where a reasonable choice is made by a reasonable individual using relevant information about the advantages and disadvantages of all the possible courses of action, in accord with the individual's beliefs."

"Shared decision making occurs when the doctor and patient share all stages of the decision making process simultaneously. In the purest form both doctor and patient reveal treatment preferences and both agree on the decision to implement." ${ }^{21}$

Box 1 Definitions of informed and shared decisions.

\section{The empirical evidence}

This is not intended to be a comprehensive account of the evidence (Coulter affords a fuller account of this literature ${ }^{11}$ ), but draws on a range of studies that previously set out to examine patient preferences for participation in decision making using a number of different methodological approaches. ${ }^{12-16}{ }^{19}{ }^{22-29}$ A further study by Kennelly and Bowling in this supplement adds to this literature. ${ }^{30}$

For example, Vick and Scott ${ }^{15}$ set out to re-examine the nature of the agency relationship in health care using the technique of conjoint analysis in which patients were asked to make discrete choices between pairwise comparisons of hypothetical "scenarios" which differed with respect to various attributes of the consultation. The questionnaire was distributed to 160 consecutive attendees in general practice and the results were based on 101 returned completed. The results showed that "being able to talk" was the most important attribute and that being involved in decision making was the least important, suggesting a distinction between the process of information evaluation and the responsibility for treatment decisions. Although patients preferred more information to less, only women and highly qualified respondents preferred to choose the treatment themselves. Older respondents and those with fewer qualifications were more likely to want the doctor to make the decision.

In a study carried out in the US, Strull et $a l^{14}$ administered questionnaires about three aspects of decision making to 210 hypertensive outpatients and to their 50 clinicians. They found that nearly half $(47 \%)$ of patients preferred the clinician to make the therapeutic decisions "using all that is known about the medicines" but without the patient's participation. One third of the patients preferred the clinician to make the decision "but strongly to consider the patient's opinion". Only $19 \%$ of the patients stated that they wished to share equally with the clinician in making the treatment decision, and 3\% wanted to make the decision themselves. More highly educated patients and patients with more severe hypertension were more likely to prefer greater discussion. Clinicians were found to underestimate patients' desire for information and discussion but to overestimate patients' desire to make decisions.

The results of such studies highlight the potential importance of a number of demographic variables. Several studies have found that younger patients and those with higher education are more likely to want to be involved in decisions. ${ }^{14-16} 2326$ Current health status and the severity of the health problem are other factors which have been found to influence attitudes towards involvement in decision making. ${ }^{15} 1623$ For example, Degner and Sloan reported that patients close to a life threatening event were more passive with respect to treatment decision preference than a comparison group of healthy individuals. ${ }^{23}$ In another study which made use of vignettes describing health states, preference for handing over control to the physician was found to be significantly greater for the vignette involving potential mortality (chest pain) than for the vignettes involving mainly morbidity (urinary 
problems) or quality of life (fertility). ${ }^{31}$ Of course, it is plausible that such findings may be confounding the age effects reported above as experience of illness and current health status are undoubtedly age dependent.

It has been suggested that the organisational aspects of the healthcare system may also have some influence on the desire for involvement in decisions. Thus, it has been argued that the desire for involvement in treatment decisions may be on the increase in all social groups alongside a decreased willingness to submit to the authority of clinicians. ${ }^{11}$

\section{Discussion}

The evidence suggests that there are a multitude of factors determining patients' desire for involvement in decision making and that there may be differences between the desire for receiving information (the process of information evaluation) and the desire to take responsibility for the treatment decision itself. Within a framework which sets out to increase patient autonomy and to involve patients more fully in their own care, it naturally follows that patient preferences over their involvement in decision making must be considered alongside their preferences over their illness or treatments for their medical condition. This is particularly important in light of suggestions that consumers of healthcare services may experience disutility from being involved in decision making about the treatment of their health problems. ${ }^{19}$ Furthermore, patient preferences on their information needs can influence their response to its provision, such that those given information who prefer not to have it may suffer greater anxiety in decision making than in the absence of such information. ${ }^{25}$

The question then becomes: how do we assess patients' preferences for participation in decision making in order to predict who will benefit from the use of decision support tools and who will not? One attempt to assess predisposition to involvement in treatment decisions is the Degner scale which was derived to characterise decision making preferences on the spectrum between paternalistic and being informed (see box 2). ${ }^{23}$ However, the Degner scale may be criticised for concentrating predominantly on the desire for responsibility for taking treatment decisions and not for information exchange. In theory, tools such as

- I prefer to make the final selection about which treatment I receive.

- I prefer to make the final selection of my treatment after seriously considering my doctor's opinion.

- I prefer that my doctor and I share responsibility for deciding which treatment is best for me.

- I prefer that my doctor makes the final decision about which treatment will be used, but seriously considers my opinion.

- I prefer to leave all decisions regarding my treatment to my doctor.

Box 2 The Degner scale. these may be used to assess preferences for participation and the amount of information given, and the structure of the consultation may be tailored to the individual patient's needs. Dowie ${ }^{32}$ uses the term "metapreference" to describe the patient's preferences over both the nature of the doctorpatient relationship and the decisions made within that relationship. He argues that research on patient involvement in decision making should be focused on "better" decisions with respect to these meta-preferences and this will not necessarily be compatible with fulfilment of the patient's health state preferences.

One potential problem with mechanisms such as these is that the patient is ill informed about what participation in decision making actually entails. This is overcome to some extent by the approach used by Dowie and colleagues on their current research on oophorectomy, whereby patients are asked directly whether they wish to receive information and answer preference questions (such as time trade off questions). While there is appeal in the directness of the Dowie approach, there remains the problem that patients may be ill informed about the advantages of participating in the treatment decision. In our focus group work with patients in atrial fibrillation we found an overriding belief that their GP knows enough about their preferences to make the decision that is best for them. In terms of agency theory, the patients appear to believe that the GP is acting as a perfect agent for them, even without eliciting their preferences explicitly.

This may fit with the traditional concept of a family GP who knows a patient for many years, but fits less well in the context of modern primary care and patient mobility. This perception also appears to be at odds with the evidence that doctors consistently underestimate patients' desire for information and that they are not good at eliciting patients' preferences. ${ }^{11}$ Furthermore, doctors' and patients' preferences for treatment options may vary markedly. ${ }^{33}$ For example, in a study of treatments for menorrhagia, Coulter et $a l^{34}$ found that, after the consultation, GPs remained unaware of the patients' treatment preference in $45 \%$ of cases. Even women expressing (in the questionnaire) a very strong preference for a treatment option appeared to have difficulty communicating this to their GP. Of course, in believing (perhaps mistakenly) that the doctor is already acting as their perfect agent, there would be little to be gained by their input into the decision. Thus, in order to make an informed decision about the extent to which they wish to participate, they must be given some indication of what the benefits of them doing so are likely to be.

Another potential problem with eliciting ex ante preferences for involvement is that many patients may have no former experience of participation in treatment decisions and, hence, their views may simply be reflecting a desire to maintain the status quo. Salkeld et $a b^{35}$ use the term "veil of experience" to describe this effect. 
This seems particularly relevant when considering the perspectives of older patients such as those in our study. Our focus group work, and subsequent piloting of a computerised decision aid, also suggest that patients may be more receptive to, and value, risk information once they have experienced its use. This also raises an associated issue of how immutable patient preferences for involvement are. While it would be surprising if people cannot change their preferences in this case, as in most others, with changing experience, there is a need to better understand this.

There is also the need to explore the reason why preferences for involvement in decision making vary between individuals or across socioeconomic groups. For example, Beisecker and colleagues offer two possible explanations of why older patients may want less input into medical decision making. ${ }^{27}$ The first is "role theory"-older patients came of age during times when the doctor was a traditional power figure, someone to be revered and obeyed. Hence, this may be an age cohort rather than an age dependent effect. The second explanation is more "developmental"-as people age they want less responsibility for treatment decisions and tend to rely more on the expertise or responsibility of others. The two explanations would appear to have quite different implications for the increased use of decision support tools in an ageing population.

\section{Conclusion}

We have provided a brief discussion of some of the issues surrounding patients' desire for involvement in decision making and illustrated these with reference to our work in Newcastle. The increased emphasis on involving patients more fully in their own care and the development of decision support tools for use in a wide range of clinical areas makes this an important area for further research. There appears to be a discrepancy between the strong belief in patient autonomy and the evidence that suggests that many patients do not wish to be active participants in making treatment decisions, even if they may be receptive to greater information exchange. It also appears that the apparent desire for a more paternalistic approach to decision making may be stronger in older and less well educated patients.

One obvious response to such findings may simply be to screen out such patients and to administer decision support tools only to those who express a desire to participate. Our own work, and that of others, suggests that this approach may be flawed as patients are often ill informed about the extent to which doctors understand their preferences and, hence, the benefits of participating more fully in the consultation. Furthermore, the preferences of patients with no prior experience of involvement in the decision may simply be reflecting the status quo. There are obvious equity issues here as better educated patients may already be more able to articulate their preferences to their clinician. The selective use of decision support tools would only appear to perpetuate any existing inequities.
It is also worth noting that decision support tools vary widely, from those that largely support better information exchange to those that seek to actively engage patients in making treatment choices. If preferences for information and for treatment responsibility differ, there may be a need to match better the use of decision aids to individual patient preferences for involvement.

We believe a more useful approach to the problem would be to understand better the motivation behind patients' views regarding their role in decision making. It seems there would be scope for multidisciplinary research in this area that made use of both quantitative techniques, such as conjoint analysis (see paper by Ryan $e t a l^{36}$ in this supplement) and qualitative data methods (see papers by Frewer et $a b^{37}$ and Kennelly and Bowling ${ }^{30}$ in this supplement). Such methods may be used to explore whether apparent age related differences are truly age dependent or reflect an age cohort effect, as well as exploring other factors influencing preferences for participation in decision making. There would also appear to be a role for experimental work-for example, to test to what extent the desire for risk information or involvement in treatment decisions changes with experience of its use. Further work might be needed to clarify differences between preferences for information and for responsibility for treatment decisions, and how any such differences may affect models of the doctor-patient interaction or development and evaluation of decision support tools.

While further discussion of these issues is beyond the scope of this paper, the increasing development and use of decision support tools and the shift towards patient empowerment raise a multitude of questions worthy of detailed research in an area lacking in robust studies to date.

The work upon which this paper draws (the DARTs project) was funded by a grant from the West Midlands Regional Office of the NHS Executive and Eli Lilley. We are grateful to the Commissioning Group and, in particular, to Professor Richard Lilford for their support and guidance. We would like to thank members of the DARTS team (Jane Greenaway, Philip Lowe, David Parkin, Martin Eccles, Karen Jones, Rosie Stacy, Helen David Parkin, Martin Eccles, Karen Jones, Rosie Stan,
Park, Ian Purves, Bob Sugden, and Emma Hutchinson) and other colleagues, including those in the MRC HSRC workshop, who helped in formulating our thoughts.

1 Bekker H, Thornton JG, Airey CM, et al. Informed decision making: an annotated bibliography and systematic review. Health Technol Assess 1999;3:No1.

2 Ottawa Decision Centre. http//www.iri.ca/ceu/ohdec/

3 Department of Health. Patient and public involvement in the new NHS. London: Department of Health, 1999.

new NHS. London: Department of Health, 1999 .
4 Roter DL, Hall JA, Merisca R, et al. Effectiveness of Roter DL, Hall JA, Merisca R, et al. Effectiveness of
interventions to improve patient compliance: a metainterventions to improve patient com
analysis. Med Care 1998;36:1138-61.

5 Bertakis KD. The communication of information from physician to patient: a method for increasing patient retention and satisfaction. F Fam Pract 1997;5:217-22.

6 Morris J, Royle GT. Offering patients a choice of surgery for early breast cancer: a reduction in anxiety and depression in patients and their husbands. Soc Sci Med 1988;26:5845.

7 Greenfield S, Kaplan S, Ware JE. Expanding patient involvement in care: effects on patient outcomes. Ann Intern Med 1985;102:520-8.

8 Greenfield S, Kaplan S, Ware JE. Patients' participation in medical care: effects on blood-sugar control and quality of life in diabetes. $\mathcal{F}$ Gen Intern Med 1988;3:448-57.

9 Kaplan S, Greenfield S, Ware JE. Assessing the effects of physician-patient interactions on the outcomes of chronic physician-patient interactions on the
disease. Med Care 1989;27:s110-27.

10 Rost KM, Flavin KS, Cole K, et al. Change in metabolic control and functional status after hospitalization: impact of patient activation intervention in diabetic patients. Diabetes Care 1991;14:881-9. 
11 Coulter A. Partnerships with patients: the pros and cons of shared clinical decison making. 7 Health Service Res Policy shared clinical

12 Deber R. Physicians in health care management. 8. The patient-physician partnership: decision making, problem solving and the desire to participate. Can Med Assoc f 1994;151:423-7

13 Deber R. The patient-physician partnership: 7. Changing roles, and the desire for information. Can Med Assoc $\mathscr{F}$ 1994;151:171-6.

14 Strull W, Bernard L, Charles G. Do patients want to participate in medical decision making? FAMA 1984;252:2990-4.

15 Vick S, Scott A. Agency in health care. Examining patients' preferences for attributes of the doctor-patient relationship. f Health Econ 1998;17:587-605.

16 Ende J, Kazis L, Ash A, et al. Measuring patients' desire for autonomy: decision making and information seeking preferences among medical patients. F Gen Intern Med 1989;4:23-30.

17 Robinson A, Thomson R. The potential use of decision analysis to support shared decision making in the face of
uncertainty: the example of atrial fibrillation and warfarin uncertainty: the example of atrial fibrillation and warfarin

18 Mooney G, Ryan $M$. Agency in health care: getting beyond first principles. F Health Econ 1993;12:125-35.

19 Shackley P, Ryan M. What is the role of the consumer in health care? F Soc Policy 1994;23:517-41.

20 Gafni A, Charles C, Whelan T. The physician-patien encounter: the physician as a perfect agent for the patient versus the informed treatment decision-making model. Soc Sci Med 1998;47:347-54.

21 Charles C, Whelan T, Gafni A. What do we mean by partnership in making decisions about treatment? $B M \mathcal{F}$ 1999;319:780-2.

22 Miller SM. When is a little information a dangerous thing? Coping with stressful life events by monitoring $\mathrm{v}$ blunting. In: Levine S, Ursin H, eds. Coping and health. New York: Plenum Press, 1980.

23 Degner LF, Sloan JA Decision making during serious illness: what role do patients really want to play? f Clin Epidemiol 1992;45:941-50.

24 Degner LF, Kristjanson LJ, Bowman D, et al. Information needs and decisional preferences in women with breast cancer. $\mathcal{F A M A}$ 1997;277:1485-92.
25 Miller SM, Mangan CE. Interacting effects of information and coping style in adapting to gynaecologic stress: should the doctor tell all? I Personality Soc Psychol 1983;45:22336

26 Blanchard C, Labrecque MS, Ruckdeschel JC, et al. Information and decision-making preferences of hospitalized adult cancer patients. Soc Sci Med 1988;27:1139-45.

27 Beisecker A. Aging and the desire for information and input in medical decisions: patient consumerism in medical encounters. Gerontologist 1988;28:330-55.

28 Cassileth B, Zupkis R, Sutton-Smith K, et al. Information and participation preferences among cancer patients. Ann Intern Med 1980;92:832-6.

29 Ryan M, Farrar S. Using conjoint analysis to elicit preferences for health care. BMf 2000;320:1530-3.

30 Kennelly C, Bowling A. Suffering in deference: a focus group study of older cardiac patients' preferences for treatment and perceptions of risk. Quality in Health Care 2001; 10(Suppl I):i23-8.

31 Deber R, Kraetschmer N, Irvine J. What role do patients wish to play in treatment decision making? Arch Intern Med 1996;156:1414-20.

32 Dowie J. Evaluating programs designed to deliver evidencebased and preference driven guidance in the clinical setting: the role of patient's meta-preferences. Discussio paper presented to INSERM Workshop, April 2000.

33 Montgomery AA, Fahey T. How do patients' treatment preferences compare with those of clinicians? Quality in Health Care 2001;10(Suppl I):i39-43.

34 Coulter A, Peto V, Doll H. Patients' preferences and general practitioners' decisions in the treatment of menstrual disorders. Fam Pract 1994;11:67-74.

35 Salkeld G, Ryan M, Short L. The veil of experience. Do consumers prefer what they know best? Health Econ 2000; 9:267-70.

36 Ryan M, Bate A, Eastmond CJ, et al. Using discrete choice experiments to elicit preferences. Quality in Health Care 2001;10(Suppl I):i55-60.

37 Frewer LJ, Salter B, Lambert N. Understanding patient's preferences for treatment: the need for innovative method ologies. Quality in Health Care 2001;10(Suppl I):i50-4. 